\title{
Avrupa Dokümantasyon Merkezleri: İstanbul Üniversitesi Hukuk Fakültesi Avrupa Hukuku Araştırma ve Uygulama Merkezi Örneği
}

\author{
An Example of European Documentation Centres: University \\ of Istanbul, Faculty of Law Centre for Research and Practice in \\ European Law
}

\author{
Pervin DEDELER BEZIRCi
}

\begin{abstract}
Öz
Ülkemizde yaklaşık 1970'li yıllardan beri var olan Avrupa Dokümantasyon Merkezleri (EUi)'nin önemini vurgulayan bu çalışmada, Avrupa Dokümantasyon Merkezleri'nden biri olan Istanbul Üniversitesi Hukuk Fakültesi Avrupa Hukuku Araştırma ve Uygulama Merkezi tanıtılmakta ve EUi statüsü gereği yapmakta olduğu faaliyetler ve Merkez Kütüphanesinin koleksiyonu ve kullanıcılara sunduğu hizmetler hakkında bilgiler verilmektedir.
\end{abstract}

Anahtar sözcükler: Avrupa Dokümantasyon Merkezi, İstanbul Üniversitesi Hukuk Fakültesi, Avrupa Hukuku Araştırma ve Uygulama Merkezi, Avrupa Dokümantasyon Merkezi, Hukuk kütüphaneleri

\begin{abstract}
Among the European Documentation Centres being located in Turkey, the University of Istanbul Faculty of Law Centre for Research and Practice in European Law has been introduced. The collection of the Library of the Centre, and the extent of the library services were also explained.

Keywords: European Documentation Center, University of Istanbul, Faculty of Law, Centre for Research and Practice in European Law, European Documentation Center, Law libraries
\end{abstract}

\section{Giriş}

Dokümantasyon (belge bilim), belge işleme ve belgelendirmedir. Bilginin kaydedildiği her nesneye belge denilmektedir. Kayda geçmiş bilgiye dayalı hizmet verme işini

*Dr.; İstanbul Üniversitesi Hukuk Fakültesi Avrupa Hukuku Araştırma ve Uygulama Merkezi EUi (Avrupa Dokümantasyon Merkezi). (pervin71@hotmail.com) 
kütüphane ve enformasyon bilimi yerine getirir. Dokümantasyon merkezi, belirli ve sınırlı bir çevrenin ya da herkesin yararlanması için, yazılı, basılı, görsel işitsel ve çizgisel her türden yayınları toplayan, düzenleyen, en elverişli yararlanma ortamını yaratacak araçları ve yöntemleri kullanarak çevresindekilere ulaştıran kuruluştur. Arşiv ve kütüphanelerde birincil belgeler ağırlıktadır (kitap, dergi vs.) Dokümantasyon merkezleri ikincil belgeler üretir ve belgelerin içeriğine ağırlık verir. İşi kitap ve dergi toplamak değil toplanmış eserlerin içeriğini kütüphanelerin yapamayacağı şekilde analiz etmektir. Enformasyon merkezlerinin birinci işi ise bilgi vermektir. İnsanların almak istediği bilgileri bulup kullanıcıya sunar.

Bilgi bilimi ve bilgi teknolojisi, insan ve örgütlü bilgi arasındaki ilişkilerin kurumsal, deneysel ve işlemsel yönden incelenmesiyle ilgilidir. Bilgi bilimi bilgiye optimum düzeyde yaklaşımı ve bilginin optimum düzeyde kullanımını sağlamak amacıyla, bilginin özelliklerini ve bilgi akışını yöneten ve bilgi işleme yollarını arayan bir bilim dalıdır.

Enformasyon kaynakları, bilgi depolayan, bilgiyi düzenleyen ve bilgiyi istendiğinde iletendir. Kütüphaneler ve dokümantasyon merkezleri de, enformasyon üretilmesi, düzenlenmesi, kullanılması amacıyla kurulmuş enformasyon sisteminin parçalarıdır.

Bilginin kullanıcıya ulaştırılması aşamasında birincil dağıtıcılar ve ikincil dağıtıcılar vardır. Basımevi, kitapçı, belge dağıtımı birincil dağıtıcılar, kütüphaneler, enformasyon merkezleri, arşivler ise ikincil dağıtıcılardır (Dedeler, 2001, s.1).

İşte bu noktalardan hareketle Avrupa Birliği, bilgiyi kamuoyuna yaymak için Avrupa Birliği Dokümantasyon Merkezlerini ve Bilgi Merkezlerini ortaya çıkarmıştır. Avrupa Birliği üyeliği sürecindeki Türkiye de Avrupa Birliği'nin yapısını, işleyişini ve politikalarını daha iyi bilmek ve analiz etmek durumundadır. Bu amaçla kurulan Avrupa Dokümantasyon Merkezlerinden biri olan İstanbul Üniversitesi Hukuk Fakültesi Avrupa Hukuku Araştırma ve Uygulama Merkezi (İAHAUM) de tam üyelik sürecinde gereksinim duyulan bilgi desteğini sağlamayı hedeflemektedir.

Konuyu netleştirmek için öncelikle Avrupa Dokümantasyon Merkezlerinin işlevlerine kısaca değinilecek ve daha sonra IAHAUM hakkında bilgiler verilecektir.

\section{Avrupa Dokümantasyon Merkezleri}

Avrupa Birliği, halkın bilgiye erişimini kolaylaştırma politikası çerçevesinde pek çok ülkede öncelikle üniversite çevresindeki araştırmacılardan gelen talepleri karşılamak amacıyla, Avrupa Dokümantasyon Merkezleri (EUi)'ni kurmuştur.

Avrupa bütünleşmesi ile ilgili araştırma ve eğitimi teşvik amacıyla, üniversitelerin de talebi üzerine kurulan bu birimlerin temel amacı, Avrupa Birliği konusunda araştırma yapmak isteyenlerin bilgi intiyacını karşılamak ve Avrupa Birliği yayınlarını kullanıcılara sunmaktır. 
Avrupa Dokümantasyon Merkezleri, kendilerine düzenli olarak ve ücretsiz gönderilen Avrupa Birliği ( $A B$ ) yayınlarından herkesin yararlanabilmesi için, üniversite üyelerinin ve ilgili kişilerin kolayca ulaşabilecekleri merkezi noktalarda yer almaktadır ve herkesin erişimine açıktır.

Başlarında yabancı dil bilen bir uzman bulunmakta, Merkezden sorumlu olan bir kişi tasnif, fişleme, kataloglama gibi kütüphanecilik hizmetleri ile birlikte, AB konularında enformasyon ve dokümantasyon hizmetleri de vermektedir.

Avrupa Dokümantasyon Merkezleri, kuruluşlarının ardından AB yayınlarının kendilerine hangi dilde gönderilmesini istediklerini Avrupa Komisyonu'na bildirmekte ve yayınlar düzenli olarak Merkezlere yollanmaktadır.

Özellikle üniversitelerde, Avrupa bütünleşmesi ve Avrupa sorunları üzerine konferans, toplantı ve seminerlerin düzenlenmesinde bu merkezlerin yardımcı olmaları kuruluş amaçları arasında yer almaktadır.

Türkiye'de de çeşitli üniversite ve sivil toplum kuruluşları bünyesinde Avrupa Entegrasyonu ile ilgili araştırma ve eğitimi teşvik etmek amacıyla Avrupa Komisyonu tarafından desteklenen 13 Avrupa Dokümantasyon Merkezi yedi ilde hizmet vermektedir (Avrupa Birliği Türkiye Delegasyonu, 2009). Bunlardan biri de İstanbul Üniversitesi Hukuk Fakültesi Avrupa Hukuku Araştırma ve Uygulama Merkezi (İAHAUM)'dir.

\section{İstanbul Üniversitesi Hukuk Fakültesi Avrupa Hukuku Araştırma ve Uygulama Merkezi (IAHAUM)}

\section{Kuruluş Amaçları ve Faaliyetleri}

1973 yılında kurulan IAHAUM'nin amacı, AB hukuku ve bütünleşme konularını incelemek ve bu alanda araştırma ve çalışmalar yapmaktır. IAHAUM, bu amacı gerçekleştirebilmek için seminerler, konferans ve kolokyum ile paneller düzenlemekte, bu konulara ilişkin yayınlar yapmakta, araştırmalar için komisyonlar kurmaktadır. Uğraştığı konularla ilgili arşiv ve kütüphane oluşturmak, çalışmalarının önemli bir bölümünü oluşturur.

Daha önce İstanbul Üniversitesi Hukuk Fakültesi Yönetim Kurulu tarafından belirlenen statü ile yönetilen IAHAUM, 10 Eylül 2006 tarihli 26285 sayılı T.C. Resmi Gazetesi'nde İstanbul Üniversitesi Hukuk Fakültesi Avrupa Hukuku Araştırma ve Uygulama Merkezi Yönetmeliği'nin yayınlanmasından itibaren bu yönetmeliğe göre yönetilmektedir.

Merkez faaliyetleri başlıklar itibariyle şöyledir;

1. Avrupa hukukuna ve Avrupa Birliğine ilişkin ulusal ve uluslararası kolokyum, sempozyum, seminer, konferans ve kongre düzenlemek ve bu tür çalışmalara katılmak, 
2. Avrupa hukukuna ilişkin konularda Türkçe ve/veya yabancı dilde her çeşit yayın yapmak,

3. Avrupa hukuku araştırmaları için geçici veya sürekli komisyonlar oluşturmak,

4. Avrupa hukukuna ilişkin gerekli arşiv ve kitaplık oluşturmak,

5. Türk ve yabancı bilim insanlarına ve uzmanlara konferanslar verdirtmek, seminerler düzenlemek ve bunları yönetmek,

6. Avrupa hukukuyla uğraşan ulusal ve yabancı kurum ve kuruluşlarla işbirliği içerisinde bulunmak,

7. İstanbul Üniversitesi Sosyal Bilimler Enstitüsü nezdinde açılacak lisansüstü öğretim çalışmalarına destek vermek ve bunlara katılmak,

8. Avrupa hukukuna ilişkin olgunlaşma ve uzmanlaşma kursları açmak.

IAHAUM, AB'nin ilgili ünitelerinden doküman, süreli yayın, resmi gazete, mahkeme karar ve derlemeleri, araştırma ve inceleme raporları alan ve sistematize eden, AB'nin yetkili yayın ve dağıtım kuruluşlarınca tanınan Türkiye'deki önemli bir dokümantasyon merkezi'(EUi)dir.

Ayrıca, İstanbul Üniversitesi genelinde, disiplinler arası bir şekilde yürütülen ve Sosyal Bilimler Enstitüsü'ne bağlı olan "AB Yüksek Lisans ve Doktora Programı" Merkez tarafından koordine edilmektedir.

Yönetmeliğe uygun olarak Yönetim Kurulu en az üç ayda bir olmak üzere toplanmakta ve Merkez'in faaliyetleri, yapılması gerekenler, sorunlar, çözüm önerileri vs. hakkında görüşülmekte ve karara bağlanarak uygulanmaktadır. Ayrıca Danışma Kurulu, Merkezin çalışmalarına tavsiye niteliğinde görüş ve önerileriyle katkıda bulunmak üzere her yıl en az bir kez toplanmaktadır.

IAHAUM kamuoyunu Avrupa Hukuku konusunda bilgilendirmek, öğretim üyelerini bu konuda araştırma yapma konusunda teşvik etmek amacıyla, "Avrupa Hukuku Günleri” başlıklı yeni bir proje başlatmıştır ve sürdürülmektedir.

"Avrupa Hukuku Günleri” konulu proje en az üç yıllık bir süreci kapsayacaktır. Bu proje için yurt içi ve yurt dışından bilim adamları ve diplomatlar konferans vermek veya panellere katılmak üzere davet edilmekte, daha sonra bu metinler kitap olarak yayınlanmaktadır. Bu proje kapsamında şu ana kadar çok değerli akademisyen ve diplomatların katıldığı çok sayıda konferans ve seminer düzenlenmiştir ve yenileri için hazırlıklar sürmektedir**.

\footnotetext{
** IAHAUM faaliyetlerinin ve yapılan seminerlerin tüm detayları için bkz. http://www.istanbul.edu.tr/ merkezler/iahaum/index.htm
} 


\section{IAHAUM Kütüphanesi}

\section{Sınıflandırma ve Yerleştirme Sistemi}

Yayınların tümü kataloglara geçirilmiştir. Kataloglama işlemi 1990-2000 yılları arasında IAHAUM için özel olarak hazırlanan bilgisayar programına yüklenmiştir. 2000 yılından itibaren ise Merkezimizde, İ.Ü. Merkez Kütüphanesi tarafından hazırlatılan kütüphane programı kullanılmaktadır. Halen kullanılmakta olan bu program günümüz teknolojisine uygun olup, pratik ve hızlı işlem yapabilmeyi mümkün hale getirmiştir. Kitaplara, sekiz değişik arama unsuru (kitap adı, konu, yazar adı, soyadı, yayınlayan, yayın yeri vs.) kullanılarak, bilgisayardan ulaşılabilmektedir. Bu program ile araştırmacılar, İHAUM'ne gelen ve kayıtlara girmiş olan tüm yayınlardan hızlı ve kapsamlı şekilde yararlanabilmekte; ayrıca İstanbul Üniversitesi'nin halen mevcut olan ağ sistemi içinde olan IAHAUM Kütüphanesi kayıtlarına herhangi bir yerden internet bağlantısı ile erişebilmektedirler.

Kitapların kataloglama işlemi için AAKK2 kullanılmaktadır. Belgeler konu başlıkları listesindeki konuları içermekte, her konu kendi içinde tarih ve $A B$ Komisyon'unun verdiği final numarasına göre ve özel konu başlıkları listesine göre numaralandırılarak etiketlenmekte ve daha sonra mevcut olan açık raf sistemine uygun bir şekilde numara sırasına göre raflara yerleştirilmektedir. Araştırmacı, özel konu başııları listesinden ya da bilgisayar kayıtlarından aradığı konunun numarasını ve yerleştirildiği rafı tespit edip, aradığı yayını rahatça bulabileceği gibi, mevcut sistemi nasıl kullanacağı ve araştırdığı bilgiye nasıl ulaşacağı konusunda uzman kütüphaneciye danışarak da aradığı bilgiye erişebilmektedir.

Süreli yayınlar ise, açık raf sistemine uygun şekilde, kutuların üzerine isimleri yazılarak ve her kutu kendi içinde tarih sırasına göre dizilerek alfabetik sıraya göre düzenlenmiş ve yerleştirilmiştir. Tüm süreli yayınlar, süreli yayın izleme kutusuna yerleştirilen, süreli yayın izleme kartlarına, sayıları ve tarihleri kayıt edilmek suretiyle işlenmektedir.

Ayrıca, çeşitli topluluk organlarının ve komitelerin toplantı tutanakları, bültenler ve seri yayınlar aynı kod numarası ile klasörler ve kutular içinde kapalı dolaplarda pratik kullanıma hazır şekilde saklanmaktadır.

\section{Koleksiyon}

$A B$ Hukukuna ait şerh, monografi ve yıllık raporları ve $A B$ yayın bürosundan gönderilen iktisat, sanayi, tarım, çevre ve kültür konularına ilişkin kitaplar bulunmaktadır.

Ayrıca, Avrupa Birliği mevzuatıyla ilgili dokümanlar, bilimsel ve teknik yayınlar, istatistikler, çeşitli konularda hazırlanmış çalışmalar ve broşürlerden oluşmaktadır. Koleksiyondaki yayınlardan bazıları şunlardır: 
$\checkmark$ Avrupa Birliği Resmi Gazetesi (Official Journal of the European Union : Legislation \& Information And Notices); L Serisi (Legislation): Avrupa Birliği

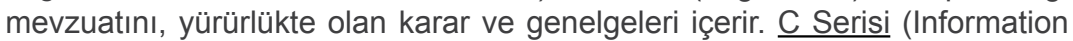
and Notices): Avrupa Komisyonu mevzuat teklifleri, Ekonomik ve Sosyal Komite'nin önergelerinden bazılarını ve Euro'nun günlük değerini içerir.

$\diamond \quad$ Komisyon Raporları (European Commission Com Documents); Yasa önerileri, politika belirleyici dokümanlar ve uygulama raporları içerir.

$\diamond$ Avrupa Parlamento Müzakereleri (Debates of the European Parliament); Avrupa Parlamentosu'nun tam oturumlarında gerçekleşen tartışma ve konuşmaları içerir.

$\diamond$ Eurostat Elektronik Kütüphane (Eurostat Electronic Library); Ekonomi, finans, enerji, endüstri, tarım, dış ticaret, nüfusbilim ve daha pek çok konudaki istatistikleri içerir.

$\diamond \quad$ Avrupa Birliği Bülteni (Bulletin of the European Union); Komisyon'un ve diğer Avrupa Birliği kurumlarının aktivite ve gelişmelerini rapor eder.

$\diamond \quad$ Yıllık Raporlar; Genel Rapor, Tarım Raporu, Rekabet Raporu, İssizlik Raporu, Avrupa Yatırım Bankasının yıllık faaliyet raporları, şeklinde yayınlanırlar. Başlıca önemli Topluluk politikaları üzerine bir yıl içinde yapılan faaliyetleri, çalışmaları, alınan karar ve teklifleri açıklayan önemli bir referans kaynağıdır.

$\diamond \quad$ Avrupa Adalet Divanı Mahkeme Kararları (European Court of Justice Court Reports); Antlaşmaların uygulama ve yorumunda kanunun dikkate alınmasını sağlayan Adalet Divanı'nın mahkeme kararları.

$\diamond \quad$ Panorama Katalogu; Topluluğun önemli imalat sanayi sektörleriyle ilgili bilgi ve istatistikî verileri içerir.

$\diamond$ İstatistikler; Topluluk İstatistik Ofisinin çeşitli konulardaki istatistiklerdir. (Dış Ticaret, Tarım, Sanayi, Para ve Finans, Yıllık Cep İstatistiği gibi)

Bu yayınların yanı sıra; Avrupa Birliği kurumlarının çıkartmış olduğu, Bölgeler Komitesi Raporları (Committee of the Regions, COR Opinion Reports) ve Ekonomik ve Sosyal Komite Dokümanları (Economic and Social Committee, ESC Documents) koleksiyon içindeki diğer önemli kaynaklardan sadece birkaçıdır.

Ayrıca, Ankara Üniversitesi Avrupa Toplulukları Araştırma ve Uygulama Merkezi, Avrupa Komisyonu Türkiye Temsilciliği, Başbakanlık DPT, İktisadi Kalkınma Vakfı, İstanbul Ticaret Odası, Marmara Üniversitesi Avrupa Topluluğu Enstitüsü, Türk Sanayicileri ve İşadamları Derneği, Türkiye İşveren Sendikaları Konfederasyonu, Türkiye Ticaret Sanayi, Deniz Ticaret Odaları ve Ticaret Borsaları Birliği ve Türkiye 
Metal Sanayicileri Sendikası gibi çeşitli kuruluşlardan bağış olarak gelen yayınlarda IAHAUM kütüphane koleksiyonu arasındadır ${ }^{* * *}$.

\section{Kullanıcı Hizmetleri}

Merkez, AB konusunda çalışmakta olan üniversite bünyesindeki öğretim üyeleri, yüksek lisans ve doktora öğrencilerinin yanı sıra, çeşitli özel ve kamu kurumlarından gelen araştırmacılara, gazetecilere ve konu ile ilgili bilgi edinmek isteyen herkese hizmet vermektedir.

Araştırmacıların Merkez bünyesindeki çalışmaları sırasında 1997 yılından bu yana sürmekte olan internet hizmetiyle, mevcut bilgisayarları kullanarak web üzerinde tarama yapması ve CD taramaları mümkün olmakta ve fotokopi makinesini kullanabilmektedirler.

AB yayınlarından Merkezimize fazla sayıda gelenler araştırmacılara ve ilgilenenlere dağıtılmaktadır.

$A B$ ve diğer ilgili kuruluşlar tarafından $A B$ ile ilgili çeşitli konularda düzenlenen seminer, konferans, toplantı ve diğer bilimsel faaliyetler elektronik posta ve afişler yoluyla ilgililere duyurulmaktadır.

AB'nin enformasyon merkezleri başta olmak üzere uluslararası dokümantasyon merkezleri, Türkiye'deki elçiliklerin ve kültür merkezlerinin, özel ve kamu kuruluşlarının kütüphane ve enformasyon merkezleri ile yakın ilişkiler kurarak, enformasyon hizmetlerinde işbirliği ve yardımlaşmayı sağlamak hizmetlerimiz arasındadır.

\section{Personel}

İHAUM personel kadrosunda bir müdür, bir müdür yardımcısı, beş yönetim kurulu üyesi, bir uzman kütüphaneci, bir sekreter ve bir hizmetli görev yapmaktadır.

\section{Kaynakça}

Avrupa Birliği Türkiye Delegasyonu (2009). Avrupa dokümantasyon merkezleri. 2 Mart 2009 tarihinde http://www.avrupa.info.tr/AB_ve_Turkiye/AB_Bilgi_Agi,Ab_Bilgi_Agi_Sayfalar. html?pageindex $=3$ adresinden erişildi.

Dedeler, P. (2001). IAHAUM İstanbul Üniversitesi Avrupa Hukuku Araştırma ve Uygulama Merkezi. İstanbul: Beta.

\footnotetext{
***iAHAUM kütüphane koleksiyonu ile ilgili detaylı tarama için bkz. http://www.kutuphane.istanbul.edu.tr
} 
